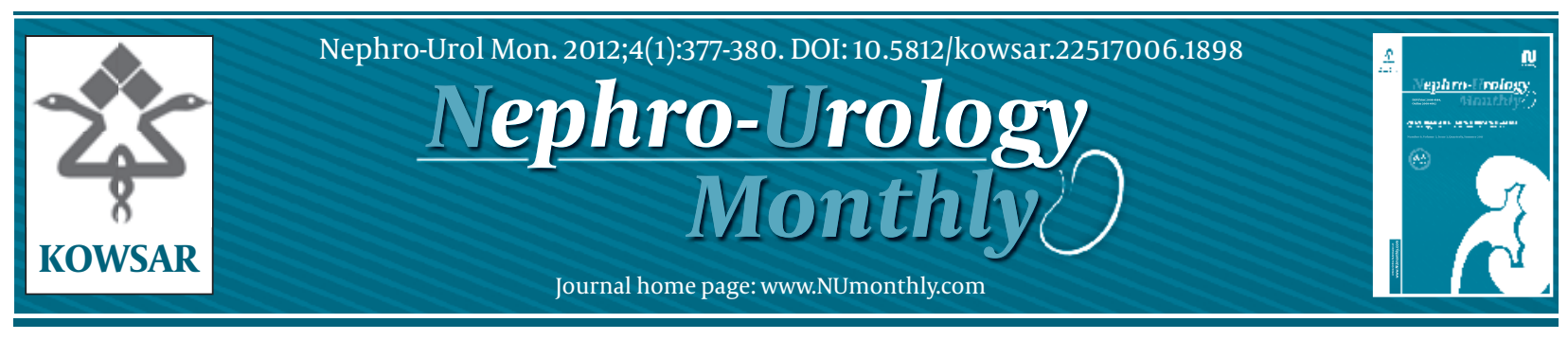

\title{
Prevalence of Testicular Microlithiasis in Males Aged 0 to 18 Years Re- ferred for Scrotal Sonography
}

\author{
Joery Goede ${ }^{1^{*}}$, Hadassa A. Hofman ${ }^{1}$, Alice M. Wagenvoort ${ }^{2}$, Frank H. Pierik ${ }^{3}$, Wilfried W.M. \\ Hack $^{1}$ \\ ${ }^{1}$ Department of Paediatrics, Medical Centre Alkmaar, Alkmaar, Netherlands \\ ${ }^{2}$ Department of Radiology, Medical Centre Alkmaar, Alkmaar, Netherlands \\ ${ }^{3}$ Netherlands Organisation for Applied Scientific Research TNO, Delft, Netherlands
}

\begin{tabular}{l}
\hline A R T I C L E I N F O \\
\hline Article type: \\
Original Article \\
\hline Article history: \\
Received: 15 Jul 2011 \\
Revised: 26 Jul 2011 \\
Accepted: 04 Aug 2011 \\
\hline
\end{tabular}

Keywords:

Prevalence

Testicular Neoplasms

Ultrasonography

\begin{abstract}
A B S T R A C T
Background: Testicular microlithiasis (TM) is a relatively uncommon and usually asymptomatic condition that is characterized by multiple $1-3 \mathrm{~mm}$ nonshadowing echogenic foci within the parenchyma of the testis.

Objectives: The prevalence of testicular microlithiasis was assessed retrospectively in males ranging from 0-18 years who had been referred for scrotal ultrasound.

Materials and Methods: Scrotal ultrasound examinations were performed in males aged 0-18 years old, producing 401 scans in 363 patients. The accumulated data included referring specialist, indication for sonography, consultant radiologist, number of images available for review of the left and right testis, associated anomalies, histological results, and testicular tumor markers.

Results: Testicular microlithiasis was found in 21 patients (5.8\%). The mean age of the patients with and without testicular microlithiasis was 11.3 and 6.7 years, respectively $(P=0.000)$. Significantly more images were available for patients with testicular microlithiasis $(P=0.000)$, yet only 8 of the 21 cases $(38.1 \%)$ were identified by the consultant radiologists. None of the boys with testicular microlithiasis were found to have a testicular malignancy.

Conclusions: Our study showed a prevalence of testicular microlithiasis of 5.8\% in symptomatic boys. The prevalence seemed to increase with age. Consultant radiologists are advised to be more vigilant towards testicular microlithiasis and to scan and store a sufficient number of imaging planes during ultrasonography.
\end{abstract}

Copyright $\odot 2012$, Kowsar M.P.Co. All rights reserved.

Implication for health policy/practice/research/medical education:

The prevalence of testicular microlithiasis is $4.7 \%$ in boys aged $0-18$ years who were referred for scrotal sonography and seemed to increase with age. Since testicular microlithiasis migth be associated with testicular malignancies and infertility, consultant radiologists are advised to be more vigilant towards testicular microlithiasis and to scan and store a sufficient number of imaging planes during ultrasonography.

Please cite this paper as:

Goede J, Hofman HA, Wagenvoort AM, Pierik FH, Hack WWM. Prevalence of Testicular Microlithiasis in Males Aged 0 to 18 Years Referred for Scrotal Sonography.Nephro-Urol Mon.2012;4(1):377-80. DOI:10.5812/kowsar.22517006.1898

* Corresponding author: Joery Goede, Medical Centre Alkmaar, Department of Paediatrics, Wilhelminalaan 12, 1815, JD Alkmaar, Netherlands.Tel: +31-725484444, Fax:+31-725482190, E-mail: j.goede@mca.nl

DOI:10.5812/kowsar.22517006.1898

Copyright $\odot 2012$, Kowsar M.P.Co. All rights reserved.

\section{Background}

Testicular microlithiasis (TM) is a relatively uncommon and usually asymptomatic condition that is characterized by multiple 1-3-mm nonshadowing echogenic foci within the parenchyma of the testis (1). These foci are mainly attributed to calcification within the lumina of 
the seminiferous tubules. TM has been described in association with numerous conditions, such as cryptorchidism, testicular torsion, varicocele, Down syndrome, pseudoxanthoma elasticum, and Klinefelter syndrome (2-6). Some authors have suggested that TM is strongly associated with testicular malignancy and infertility (7).

The prevalence of TM ranges from 0.6-9\% in symptomatic adults $(8,9)$. To date, only 2 retrospective studies have been conducted in symptomatic boys, reporting prevalences of $1.9 \%$ and $2.0 \%(10,11)$.

\section{Objectives}

The aim of this retrospective study was to assess the prevalence of TM in symptomatic males aged 0-18 years, in whom scrotal sonography was performed for a variety of scrotal complaints. In addition, we investigated whether the consultant radiologists who performed ultrasonography documented TM.

\section{Materials and Methods}

\subsection{Study Design}

The radiology department database of the Medical Centre Alkmaar was searched for all computerized testicular or scrotal sonographs that were performed on males aged 0-18 years between February 2004 and November 2008.

\subsection{Inclusion and Exclusion Criteria}

Patients referred for scrotal sonography were included in the study. Indications included undescended testis (UDT), scrotal swelling, and pain.

\subsection{Definition of TM}

Classical TM (CTM) was defined by at least 5 echogenic foci varying from $1-3 \mathrm{~mm}$ in 1 field of view. We defined the grading system of the patients with CTM as follows: 5-10 microliths $=$ grade I, 10-20 microliths $=$ grade II, and $>20$ microliths = grade III (7). Patients who had less than $3 \mathrm{mi}-$ croliths were classified as having limited TM (LTM).

\subsection{Data Collection}

The accumulated data included the referring specialist, the indication for sonography, the number of planes stored, and the consultant radiologist. All ultrasound examinations were carried out by consultant radiologists with high-resolution sonography on a range of scanners. Standard views were obtained and stored. There was no departmental protocol for the examination and storage of images. Color Doppler ultrasonography was only performed in selective cases and was therefore not analyzed.

A retrospective analysis was performed in which all ultrasound images were reviewed by 1 trained observer (HAH) who screened for microliths. The testicle involved, the number of calcifications, and the focal or diffuse nature of the microcalcifications were determined. If there was uncertainty about the presence of microliths, the images were reviewed by a second investigator (JG). The number of images available for review of the left and right testis (longitudinal and transverse) were noted. Other pathological findings were also recorded, such as varicoceles and epididymis cysts. After the images were screened for microliths, the findings were cross checked with the existing report by the consultant radiologist.

\subsection{Statistics}

The prevalence of TM in the referred population was expressed as the percentage of cases in the study group. If multiple ultrasounds were obtained from a patient, only the first examination was included in the analysis. Means were compared using a Mann-Whitney test with SPSS for Windows (Version 14.0, IBM Corporation, Armonk, NY, USA).

\section{Results}

A total of 401 ultrasound scans were obtained for 363 patients during the study period. In 23 boys, ultrasonography was performed twice; in 4 boys, it was performed 3 times; and, in one boy, it was performed 8 times. In 26 of the 401 ultrasound scans, only 1 testicle was examined (7 left-sided, 19 right-sided). The results are summarized in Table 1.

\subsection{Indications}

Indications for scrotal sonography were UDT ( $\mathrm{n}=198$, $49.4 \%$ ), scrotal swelling ( $n=100,24.9 \%)$, pain $(n=83$, $20.7 \%$ ), and miscellaneous ( $\mathrm{n}=20,5.0 \%)$. TM was not an indication in any of the cases. Referring specialists included general practitioners $(n=63,15.7 \%)$, pediatricians $(n=250,62.3 \%)$, surgeons $(n=24,6.0 \%)$, and urologists ( $n$ $=64,16.0 \%$ ).

\subsection{Prevalence of TM}

TM was diagnosed in 21 patients (5.8\%). The mean age of the patients with and without TM $( \pm$ SD) was $11.3( \pm 4.9)$ and $6.7( \pm 5.6)$ years, respectively $(P<0.001)$. The youngest boy with TM was diagnosed almost immediately after birth. CTM was detected in 17 patients (4.7\%), and LTM was detected in 4 patients (1.1\%). Unilateral and bilateral CTM were detected in 10 (47.6\%) and 7 (33.3\%) of the 21 patients, respectively. The distribution of the microliths in the testicular parenchyma was focal in $3(17.6 \%)$ and diffuse in 14 (82.4\%) of the 17 patients with CTM. Figure 1 shows a representative example of CTM that was found in our study.

\subsection{Other Ultrasound Findings}

Ultrasonography was performed by 17 different consultant radiologists with a total of 4 different ultrasound scanners. In 8 of the 21 patients (38.1\%) with TM, the condition was documented in the formal report. As shown in Table 1 , significantly more pictures $(P<0.05)$ were stored for patients with TM than for those without TM, except 


\begin{tabular}{|c|c|c|c|}
\hline & Without TM ${ }^{a}, n=342$ & With TM, $n=21$ & $P$-value \\
\hline \multicolumn{4}{|l|}{ Age, y } \\
\hline Mean \pm SD & $6.7 \pm 5.6$ & $11.3 \pm 4.9$ & $0.000^{b}$ \\
\hline Median & 6 & 12 & \\
\hline \multicolumn{4}{|l|}{ Indication, $\mathrm{n}$} \\
\hline Pain & 69 & 8 & \\
\hline Swelling & 85 & 5 & \\
\hline Undescended testis & 177 & 9 & \\
\hline Other & 11 & 0 & \\
\hline \multicolumn{4}{|c|}{ Number of pictures stored (mean \pm SD) } \\
\hline Longitudinal L & $1.39 \pm 0.70$ & $1.93 \pm 0.70$ & $0.000^{b}$ \\
\hline Longitudinal $\mathrm{R}$ & $1.43 \pm 0.70$ & $2.37 \pm 0.84$ & $0.000^{b}$ \\
\hline Transverse L & $1.02 \pm 0.75$ & $1.31 \pm 1.26$ & $0.389^{b}$ \\
\hline Transverse R & $1.03 \pm 0.72$ & $1.67 \pm 1.04$ & $0.000^{b}$ \\
\hline
\end{tabular}

${ }^{a}$ Abbreviation: TM, testicular microlithiasis

${ }^{\mathrm{b}} \mathrm{P}$-value based on the Mann-Whitney test

Figure 1. Classical Testicular Microlithiasis of the Right Testicle in a 12-Year-Old Boy With Left-Sided Torsio Testis.

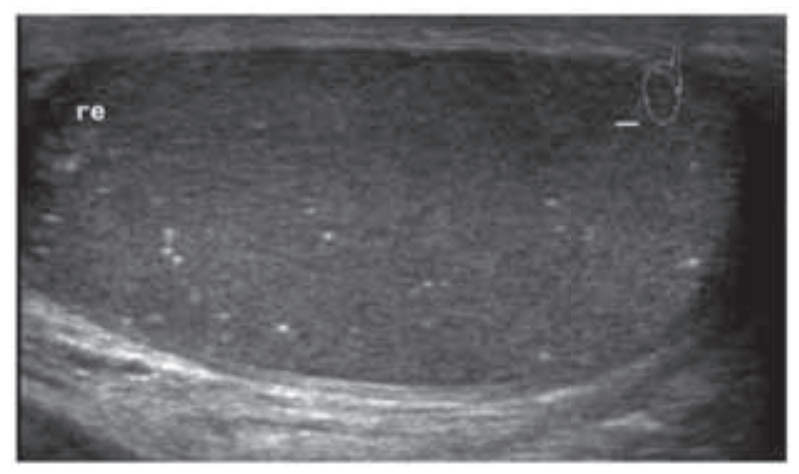

A transverse ultrasound image of the right testis showing more than 5 microliths without acoustic shadowing per sonographic plane.

for transverse pictures of the left testicle $(P=0.39)$.

\subsection{Associated Anomalies}

CTM was associated with acquired UDT $(n=1)$, congenital UDT $(n=3)$, testicular torsion $(n=3)$, a varicocele ( $n$ $=1)$, epididymitis $(n=1)$, and a hydrocele $(n=1)$. The remaining 7 patients with CTM were found to have an otherwise normal scrotal ultrasound.

One 4-year-old boy who was referred for a congenital left-sided UDT was found to have LTM of the right testicle. He was later diagnosed with Klinefelter syndrome (karyotype 47, XXY). An 11-year-old boy with bilateral CTM was known to have $18 \mathrm{q}$ syndrome and bilateral congenital UDT. Tumor markers (i.e., lactate dehydrogenase, alpha-fetoprotein, and $\beta$-human chorionic gonadotropin) were assayed in 1 patient with swelling and bilateral CTM, and the levels of these markers were within normal limits. Pathology results were not available for the patients with TM. A testicular tumor was detected in 2 of the 363 patients ( 1 bilateral testicular manifestation of Burkitt lymphoma and 1 embryonal cell tumor). Neither patient showed TM on ultrasonography.

\section{Discussion}

In our study population, the overall prevalence of TM was $5.8 \%$ and that of CTM was $4.7 \%$. The youngest boy with CTM (grade II) was diagnosed almost immediately after birth. Ultrasonography was performed because of unilateral scrotal swelling that was probably due to prenatal testicular torsion.

Leenen et al. reported a TM rate of $1.9 \%$ among 850 symptomatic boys aged 6-18 years (10). In addition, Miller et al. found a prevalence of $2 \%$ in 198 symptomatic boys under 18 years of age, whereas Goede et al. found a prevalence of $4.2 \%$ in 694 asymptomatic boys under 19 years of age $(11,12)$. For these age groups, our study revealed a slightly higher prevalence of TM and CTM (5.8\% and 4.7\% respectively). In symptomatic adults, the CTM rate varies from $0.6 \%$ to $9 \%$, whereas 2 studies found a rate of $5.6 \%$ and $2.4 \%$ in asymptomatic adults $(13,14)$. Several studies have shown an association between TM and testicular tumors. However, the natural history of asymptomatic TM is unknown, and the prognostic value of TM as a precancerous lesion is controversial. Only a few cases of preexisting asymptomatic TM in which testicular tumors developed have been reported (15). In our study group, 2 of the 363 patients were diagnosed with testicular tumors, but neither of these patients had TM.

TM is usually an incidental finding. Only $38 \%$ of cases with TM were documented by consultant radiologists. The exact pathogenesis remains unclear, and both intratubular and extratubular mechanisms have been reported (16). The microliths are presumed to be due to Sertoli cell dysfunction. In a limited number of samples, hydroxyapatite was found to be the main component in the microliths, indicating an intraluminal origin. Since the exact pathogenesis of TM is not fully understood, the typical age of onset is unknown to the best of our knowledge. In our study, boys with TM were significantly older than boys without TM (Table 1, $P=0.000$ ), which suggests that the incidence of TM increases with age. TM is associated with both benign and malignant pathologies, including UDT, varicoceles, and testicular torsion. In this study, TM was found in 4 boys with UDT, in 1 boy with a varicocele, and in 3 boys with testicular torsion. 
Moreover, TM may be associated with chromosomal disorders, such as Klinefelter and Down syndrome $(2,6)$. In our study, only 1 patient was found to have coexisting Klinefelter syndrome and LTM. One boy with Down syndrome who was aged 7 did not show any signs of TM.

This study had some clear limitations, which were related most specifically to its retrospective nature. Only digitally available sonographic pictures could be reviewed for the presence of microcalcifications, and moving images were not accessible for analysis. The presence of some echogenic areas that were caused by small vessels may be mistaken for limited TM. The actual prevalence of TM might therefore be lower than what was calculated in this study. Furthermore, in most cases, only a limited number of planes were stored, and, therefore, some cases of TM may have been missed. Significantly more images were available for patients with TM $(P<0.05)$, yet only 8 out of 21 cases (38.1\%) were identified by consultant radiologists. Our study population was too small to apply multivariate analyses, and, due to the relatively small number of patients, we could not correct for the confounding factors of age and the number of pictures available. Therefore, it remains unclear whether TM occurs more often in certain conditions, such as UDT or torsio testis.

In this study, 149 patients were less than 4 years old. Because TM may develop at a later age, it is possible that some boys will develop TM, which would increase the prevalence of TM in the group studied. There are no generally accepted strategies for the follow up of pediatric patients with CTM or TM, as the natural history remains unclear. Until further data become available, we suggest that routine ultrasounds are conducted every 12 months for patients with CTM and that self-examinations are conducted every 3 months after the age of 15 .

Our study showed a prevalence of TM and CTM of 5.8\% and $4.7 \%$, respectively, in boys aged $0-18$ years who were referred for scrotal sonography. The prevalence of CTM seemed to increase with age. Finally, we advise consultant radiologists to be more vigilant towards TM and to scan and store a sufficient number of imaging planes during ultrasonography.

\section{Acknowledgments}

None declared.

\section{Financial Disclosure}

None declared.

\section{Funding/Support}

None declared.

\section{References}

1. Bushby LH, Miller FN, Rosairo S, Clarke JL, Sidhu PS. Scrotal calcification: ultrasound appearances, distribution and aetiology. $\mathrm{Br}$ J Radiol. 2002;75(891):283-8.

2. Aizenstein RI, DiDomenico D, Wilbur AC, O'Neil HK. Testicular microlithiasis: association with male infertility.JClin Ultrasound 1998;26(4):195-8.

3. Ganem JP, Workman KR, Shaban SF. Testicular microlithiasis is associated with testicular pathology. Urology.1999;53(1):209-13.

4. Goede J, Hack WW, Sijstermans K, Pierik FH. Testicular microlithiasis in a 2-year-old boy with pseudoxanthoma elasticum. $J$ Ultrasound Med. 2008;27(10):1503-5.

5. Nistal M, Paniagua R, Diez-Pardo JA. Testicular microlithiasis in 2 children with bilateral cryptorchidism. J Urol. 1979;121(4):535-7.

6. Vachon L, Fareau GE, Wilson MG, Chan LS. Testicular microlithiasis in patients with Down syndrome. J Pediatr. 2006;149(2):233-6.

7. Backus ML, Mack LA, Middleton WD, King BF, Winter TC, 3rd, True LD. Testicular microlithiasis: imaging appearances and pathologic correlation. Radiology. 1994;192(3):781-5.

8. Bach AM, Hann LE, Hadar O, Shi W, Yoo HH, Giess CS, et al. Testicular microlithiasis: what is its association with testicular cancer? Radiology. 2001;220(1):70-5.

9. Hobarth K, Susani M, Szabo N, Kratzik C. Incidence of testicular microlithiasis. Urology. 1992;40(5):464-7.

10. Leenen AS, Riebel TW. Testicular microlithiasis in children: sonographic features and clinical implications. Pediatr Radiol. 2002;32(8):575-9.

11. Miller FN, Rosairo S, Clarke JL, Sriprasad S, Muir GH, Sidhu PS Testicular calcification and microlithiasis: association with primary intra-testicular malignancy in 3,477 patients. Eur Radiol. 2007;17(2):363-9.

12. Goede J, Hack WW, van der Voort-Doedens LM, Sijstermans K, Pierik FH. Prevalence of testicular microlithiasis in asymptomatic males 0 to 19 years old. J Urol. 2009;182(4):1516-20.

13. Serter S, Gumus B, Unlu M, Tuncyurek O, Tarhan S, Ayyildiz V, et al. Prevalence of testicular microlithiasis in an asymptomatic population. Scand J Urol Nephrol. 2006;40(3):212-4.

14. Peterson AC, Bauman JM, Light DE, McMann LP, Costabile RA. The prevalence of testicular microlithiasis in an asymptomatic population of men 18 to 35 years old. J Urol. 2001;166(6):2061-4.

15. DeCastro BJ, Peterson AC, Costabile RA. A 5-year followup study of asymptomatic men with testicular microlithiasis. $J$ Urol. 2008;179(4):1420-3; discussion 3.

16. Drut R, Drut RM. Testicular microlithiasis: histologic and immunohistochemical findings in 11 pediatric cases. Pediatr Dev Pathol. 2002;5(6):544-50. 